\author{
Maurizio Gabrielli \\ Francesco Franceschi \\ Giuseppe Fiore \\ Marcello Candelli \\ Alessandro Armuzzi \\ Veronica Ojetti \\ Filippo Cremonini \\ Paolo Pola \\ Mario Giacovazzo \\ Antonio Gasbarrini
}

\section{Beneficial effects of Helicobacter pylori eradication on migraine: a 12-month follow-up study}

Received: 27 March 2000

Accepted in revised form: 5 February 2001

M. Gabrielli • F. Franceschi • M. Candelli

A. Armuzzi • V. Ojetti • F. Cremonini

P. Pola • A. Gasbarrini ( $($ )

Department of Internal Medicine,

Catholic University,

Largo Gemelli 1, I-00168 Rome, Italy

e-mail: angiologia@rm.unicatt.it

Tel.: +39-06-30154294

Fax: +39-06-35502775

G. Fiore • M. Giacovazzo

Department of Internal Medicine,

La Sapienza University, Rome, Italy

\begin{abstract}
Helicobacter pylori ( $H$. pylori) has been recently associated with some organic and functional vascular disorders. In particular, our group found a high prevalence of $H$. pylori in patients affected by migraine and a significant improvement of migraine symptoms after eradication of the bacterium, during a follow-up period of 6 months. However, seasonal variations may affect clinical manifestations of migraine, thus influencing our previous results. The present study evaluated the effect of $H$. pylori eradication during a 1-year follow-up period in a population of 148 consecutively enrolled migraine patients. H. pylori infection was assessed by ${ }^{13} \mathrm{C}$-urea breath test. Infected subjects underwent specific antibiotic treatment in
\end{abstract}

order to eradicate the bacterium. Frequency, intensity and duration of attacks of migraine were assessed during a 1-year follow-up period. $42 \%$ of the patients showed $H$. pylori infection. $82 \%$ resulted eradicated. Interestingly, $28 \%$ of the patients reported a disappearance of migraine during the follow-up period.

Moreover, a significant decrease of intensity, frequency and duration of the migraine attacks evaluated 2, 4, 6 and 12 months from $H$. pylori eradication was observed in the remaining patients. The beneficial effects of $H$. pylori eradication on migraine seem to be confirmed by this prolonged 1-year follow-up study.

Key words Helicobacter pylori . Migraine $\cdot$ Cytotoxins $•$ Vasospasm

\section{Introduction}

Migraine is the most frequent kind of primary headache, affecting about $18 \%$ of females and $6 \%$ of males of the general population [1]. According to the criteria established in 1988 by the International Headache Society (IHS), migraine is defined as a periodic, commonly unilateral, throbbing headache, with or without cerebral disturbance, with intervening periods of relative freedom of headache and without evidence of primary structural abnormality [2]. However, it is often under-diagnosed and under-treated [3]. Several hypotheses have been considered in order to explain its pathogenetic background. Since all of them are supported by notable scientific evidence, the vascular involvement represents the conditio sine qua non for migraine attack [4].

Gastric infection by Helicobacter pylori (H. pylori) is extremely diffused worldwide and is actually considered to be the most relevant cause of chronic gastritis and peptic ulcer [5, 6]. It is also associated with an increased risk of MALT-lymphoma and gastric cancer [7, 8]. Since spontaneous clearance of the bacterium is extremely rare, at least in the absence of specific antibiotic treatment, the infection lasts for a long time.

In the last years, $H$. pylori infection has been associated with some extradigestive pathologies, and expecially with organic and functional vascular disorders [9-16]. In particular, 
our group [11] recently reported a high prevalence of $H$. pylori infection, with particular regard to cytotoxic strains, in patients with migraine. Moreover, we reported a complete disappearance or a significant improvement of migraine in the major part of eradicated patients, during the 6-month follow-up period. Therefore, we hypothesized that the inflammatory response caused by $H$. pylori infection may affect migraine through an immune-mediated release of cytokines and other substances endowed with both vasospastic and proalgogen properties [17-26]. However, in this study we did not take into account of the presence of some confounding factors, which may affect the clinical outcome of the migraine patients, such as some environmental factors, which also include the seasonal variations [27-29]. Since the end of the follow-up period of our previous study was in the summer, a new 1-year follow-up study was necessary to avoid possible seasonal variations of migraine, which in turn may influence our previous results.

Aim of the present study was to evaluate the effect of $H$. pylori eradication during a 1-year follow-up period in a population of patients affected by migraine, thus verifying whether the eradication of the bacterium may represent a novel, encouraging approach to the management of patients with migraine.

\section{Patients and methods}

This study was a open, non-randomized trial, evaluating 148 patients affected by migraine. All patients were consecutively enrolled at the Headache Center of the La Sapienza University. Migraine was defined according to the criteria of the IHS [2]. Informed consent was obtained from each patient and the study was approved by the Ethics Committee of the Catholic University of Rome. A self-evaluation test [30] was used to assess the clinical characteristics of migraine. In particular, patients were asked to record, a daily diary, the intensity (scored from 0 to 4: 0 , minimum; 4, maximum), the duration (hours) and the frequency (days per months) of headache attacks, during the 3 months preceding the 1year follow-up medical consultation. In all patients, ${ }^{13} \mathrm{C}$-urea breath test, a noninvasive, highly sensitive and specific method to assess $H$. pylori infection [31], was performed to assess the infection status.

All $H$. pylori-positive patients underwent triple therapy with amox- icillin (500 mg qid), clarithromycin (250 mg bid) and a proton pump inhibitor (bid) for 7 days. H. pylori eradication was assessed 2 months after the end of the treatment. Intensity, duration and frequency of the attacks of migraine were re-evaluated 2 months (T1), 4 months (T2), 6 months (T3) and 12 months (T4) after H. pylori eradication.

Results are expressed as mean \pm SEM. Statistically significant differences between groups were assessed using either Student's $t$ test, when appropriate. A $p$ value $<0.05$ was considered to be significant. A $50 \%$ of symptoms improvement was expected with a power of 0.8 .

Ricerca in Medicina (Bologna, Italy), which partly supported the study, did not have any role in the collection of data, its analysis and interpretation, nor did it approve or disapprove of the manuscript for publication.

\section{Results}

We studied 148 patients affected by migraine (102 without aura and 46 with aura; 95 women and 53 men, mean age $38 \pm 10$ years).

Overall, $42 \%$ of the patients showed $H$. pylori infection (62 of 148 patients). Infected patients showed a mean age significantly higher than not-infected patients $(45 \pm 8$ vs. $31 \pm 12$ years; $p<0.001)$. Neither gender nor migraine type affected the infection status. In particular, $H$. pylori infection was detected in $38 \%$ of patients affected by migraine with aura and in $44 \%$ of subjects affected by migraine without aura.

$82 \%$ (47/57; per protocol analysis) and 76\% (47/62; intention to treat) of the patients showed H. pylori eradication 2 months after the end of the treatment. The infected patients who did not complete the eradication study ( 5 of $62 ; 8 \%$ ) were considered to be drop outs. Interestingly, 28\% (16 of 57 patients) reported a disappearance of migraine during the follow-up period. Moreover, there was a significant decrease in intensity, frequency and duration of the migraine attacks at 2 months (T1), 4 months (T2), 6 months (T3) and 12 months (T4) after $H$. pylori eradication in the remaining patients. No significant correlation was found between clinical improvement after $H$. pylori eradication and kind of migraine. Interestingly, migraine symptoms did not change significantly during the follow-up period in treated but not eradicated patients, as well as in H. pylori-negative subjects (Tables 1-3).

Table 1 Intensity of migraine attacks assessed in the 3 months preceding admission (T0), and every 2 months for 12 months (T1, T2, T3, T4) after $H$. pylori eradication. Intensity is scored from 0 to 4: 0 , minimum; 4, maximum. Intensity of migraine is compared between treated and eradicated, treated but not eradicated by $H$. pylori infection, and $H$. pylori-negative patients. Values are means (95\% CI)

\begin{tabular}{llllllll}
\hline Times & \multicolumn{2}{l}{ Negatives } & \multicolumn{2}{c}{ Not eradicated } & \multicolumn{2}{c}{ Eradicated } & $p$ value \\
\hline T0 & 2.9 & $(2.5-3.5)$ & 3 & $(2.5-3.4)$ & 3 & $(2.7-3.2)$ & NS \\
T1 & 2.8 & $(2.3-3.2)$ & 2.7 & $(2.3-3.0)$ & 2 & $(1.8-2.2)$ & $<0.01$ \\
T2 & 3 & $(2.5-3.5)$ & 2.8 & $(2.4-3.1)$ & 1.5 & $(1.3-1.7)$ & $<0.01$ \\
T3 & 3 & $(2.5-3.5)$ & 2.9 & $(2.6-3.1)$ & 1.4 & $(1.2-1.6)$ & $<0.01$ \\
T4 & 2.9 & $(2.7-3.1)$ & 3 & $(2.5-3.5)$ & 1.2 & $(1.0-1.3)$ & $<0.01$ \\
\hline
\end{tabular}

NS, not significant 
Table 2 Duration (hours) of migraine attacks assessed in the 3 months preceding admission (T0) and every 2 months for 12 months after H. pylori eradication (T1, T2, T3, T4). Duration of migraine attacks is compared between treated and eradicated and treated but not eradicated by $H$. pylori infection, and $H$. pylori-negative patients. Values are means $(95 \% \mathrm{CI})$

\begin{tabular}{|c|c|c|c|c|}
\hline Times & Negatives & Not eradicated & Eradicated & $p$ value \\
\hline T0 & $15.2(11.0-18.8)$ & $15 \quad(10.1-19.9)$ & $16 \quad(12.1-19.9)$ & NS \\
\hline $\mathrm{T} 1$ & $15 \quad(10.3-19.1)$ & $14.6 \quad(9.7-19.5)$ & $(9.6-16.4)$ & NS \\
\hline $\mathrm{T} 2$ & $15.5(11.1-20.2)$ & $16.4(10.6-22.2)$ & $(6.9-13.0)$ & $<0.05$ \\
\hline $\mathrm{T} 3$ & $15.2 \quad(9.8-19.8)$ & $15 \quad(10.1-19.9)$ & $(6.3-11.7$ & $<0.05$ \\
\hline $\mathrm{T} 4$ & $15.5(10.9-19.9)$ & $15.4(10.4-20.4)$ & $(5.8-10.2)$ & $<0.01$ \\
\hline
\end{tabular}

$N S$, not significant

Table 3 Frequency (days per month) of migraine attacks assessed in the 3 months preceding admission (T0) and every 2 months for 12 months (T1, T2, T3, T4) after $H$. pylori eradication. It is compared to the frequency after finishing the eradication treatment (T1, T2, T3) in treated and eradicated and treated but not eradicated by $\mathrm{H}$. pylori infection, and $\mathrm{H}$. pylori-negative patients. Values are means $(95 \% \mathrm{CI})$

\begin{tabular}{|c|c|c|c|c|}
\hline Times & Negatives & Not eradicated & Eradicated & $p$ value \\
\hline T0 & $7.8 \quad(5.9-9.9)$ & $7.2 \quad(4.5-9.9)$ & $(7.1-9.4)$ & NS \\
\hline $\mathrm{T} 1$ & $7.9 \quad(5.8-10.2)$ & $7.5 \quad(5.3-9.7)$ & $6.7 \quad(5.6-7.8)$ & NS \\
\hline $\mathrm{T} 2$ & $7.5 \quad(5.6-10.0)$ & $7.0 \quad(4.5-9.5)$ & $4.5 \quad(3.8-5.2)$ & $<0.05$ \\
\hline $\mathrm{T} 3$ & $(5.7-9.8)$ & $7.1 \quad(4.7-9.5)$ & $(3.4-4.6)$ & $<0.01$ \\
\hline $\mathrm{T} 4$ & $7.9 \quad(5.9-10.2)$ & $7.0 \quad(4.5-9.5)$ & $(3.3-4.3)$ & $<0.01$ \\
\hline
\end{tabular}

$N S$, not significant

\section{Discussion}

Before discussing the results of this study, it appears important to assume that patients presenting to a Headache Center (University Department) are not representative sample of migraine sufferers in the general population. Several studies, in fact, showed that migraine patients consulting headache centers are clinically different from those of general population [32].

In the previous study [11], we reported the results of admininstering of $H$. pylori eradicating treatment to a group of infected patients affected by migraine. In particular, we observed a disappearance of migraine in about $25 \%$ of the patients, as well as a significant improvement of intensity, duration and frequency of the migraine attacks, 6 months after $H$. pylori eradication. Since those results strongly suggested a role of $H$. pylori infection in the pathogenesis of migraine, a new study with a prolonged follow-up period appeared to be necessary in order to avoid possible confounding factors able to influence migraine. Some studies, in particular, proposed a seasonal variation of migraine, even though there are still conflicting results in this field [27-29], whereas the end of the follow-up period during the summer was one possible bias of our previous study.

Results from the present study confirm our previous findings. In particular, no recurrence of migraine has been observed in the majority of the patients who previously reported a disappearance of the attacks after $H$. pylori eradication, whereas more than $90 \%$ of the patients maintained a significant improvement of intensity, duration and frequency of migraine.

Since these findings suggest a possible link between presence of a long-lasting infectious disease and dismotility of cerebral arterial districts, no definitive data are available to explain such association. Nevertheless, we hypothesize that the chronic immuno-inflammatory response evoked by the infection is one of the possible mechanisms by which $H$. pylori affects migraine. Human inflammatory response to $H$. pylori, in particular, is characterized by recruitment and activation of neutrophils, monocytes, and lymphocytes into the gastric mucosa [20], which is followed by the release of a large variety of cytokines (in particular interleukins 1, 6, 8 and interferon $\gamma$ ) and other molecules endowed with proinflammatory, vasospastic, and proalgogen properties [17-26]. Interestingly, CagA-positive strains, which are predominant in patients affected by migraine [11], are able to produce significantly higher amounts of such cytokines than CagA-negative ones [33, 34]. Moreover, $H$. pylori eradication leads to a gradual decrease of the gastric infiltrate, which is followed by a decrease of cytokines, during the following 3-12 months $[35,36]$. Therefore, we hypothesize that cytokines and other proinflammatory substances released by the infection may flow into the systemic circulation, thus inducing a 
dismotility of peculiar arterial districts. H. pylori eradication would decrease the production of such substances, thus inducing the disappearance or the improvement of migraine. However, it is known that not all the patients infected by $H$. pylori are affected by migraine. The most convincing explanation for this observation can be found in the complex interaction between host and bacterium. In particular, the presence of particular factors, such as infection with CagA-positive strains in subjects with a genetic susceptibility to develop migraine, may explain the different clinical outcomes of the infection in different patients.

In conclusion, as previously reported, this study showed that standard antibiotic therapy used to eradicate $H$. pylori infection appears to significantly improve migraine symptoms in the subgroup of infected migraine patients. The antiH. pylori therapy effects could be either nonantibiotic or a consequence on other chronic infections, unknown at present to be associated with migraine. Moreover, a doubleblind cross-sectional eradication trial, which should also include the evaluation of vasoactive and proalgogen cytokines as well as the HLA genotype of the patients, remains at present necessary to verify the presence of a possible infectious origin of migraine.

Acknowledgments We thank the association Ricerca in Medicina (Bologna, Italy) for the support given to perform the study.

\section{References}

1. Ferrari MD (1998) Migraine. Lancet 351:1043-1051

2. Headache Classification Committee of the International Headache Society (1988) Classification and diagnostic criteria for headache disorders, cranial neuralgias and facial pain. Cephalalgia 8[Suppl 7]:19-34

3. Lipton RB, Stewart WF, Von Korff M (1995) Migraine impact and functional disability. Cephalalgia 15 [Suppl]:4-9

4. Blau JN (1992) Migraine: theories of pathogenesis. Lancet 339:1202-1209

5. Calam J (1994) H. pylori. Eur J Clin Invest 24:501-510

6. Gasbarrini G, Pretolani S, Bonvicini F, Gatto MRA, Tonelli E, Megraud $\mathrm{F}$ et al (1995) A population based study of $H$. pylori infection in a European country: the San Marino Study. Relations with gastrointestinal diseases. Gut 36:838-844

7. Bouzourene H, Haefliger T, Delacretaz F, Saraga E (1999) The role of Helicobacter pylori in primary gastric MALT lymphoma. Histopathology 34(2):118-123

8. Danesh J (1999) Helicobacter pylori infection and gastric cancer: systematic review of the epidemiological studies. Aliment Pharmacol Ther 13(7):851-856

9. Gasbarrini A, Serricchio M, Tondi P, Gasbarrini G, Pola P (1996) Association of $H$. pylori infection with Raynaud phenomenon. Lancet 348:966-967

10. Gasbarrini A, De Luca A, Fiore G, Franceschi F, Ojetti V, Torre ES et al (1998) Primary headache and Helicobacter pylori. Int J Angiol 7(4):310-314
11. Gasbarrini A, De Luca A, Fiore G, Gabrielli M, Franceschi F, Ojetti V et al (1998) Beneficial effects of Helicobacter pylori eradication on migraine. Hepatogastroenterology 45(21):765-770

12. Mendall MA, Goggin PM, Molineaux N, Levy J, Toosy T, Strachan D et al (1994) Relation of $H$. pylori infection and coronary heart disease. Br Heart $\mathbf{J}$ 71:437-439

13. Mendall MA, Patel P, Carrington D, Strachan D, Leatham E, Molineaux N et al (1995) Association of H. pylori and Clamydia pneumoniae infection with coronary heart disease and cardiovascular risk factors. Br Med J 311:711-714

14. Pasceri V, Cammarota G, Patti G, Cuoco L, Gasbarrini A, Grillo RL et al (1998) Association of virulent Helicobacter pylori strains with ischaemic heart disease. Circulation 97:1675-1679

15. Gasbarrini A, Serricchio M, Tondi P, Franceschi F, Ojetti V, Sanz Torre ES et al (1998) Helicobacter pylori infection and vascular diseases. Ital J Gastroenterol Hepatol 30[Suppl 3]:S307-S309

16. Gasbarrini A, Franceschi F, Armuzzi A, Ojetti V, Torre ES, De Lorenzo A et al (1999) Extradigestive manifestations of Helicobacter pylori gastric infection. Gut 45[Suppl 1]:I9-I12

17. Crabtree JE, Shallcross TM, Heatley RV, Wyatt JL (1991) Mucosal tumor necrosis factor alpha and interleukin-6 in patients with $H$. pylori associated gastritis. Gut 31:1473-7147
18. Crabtree JE (1996) Immune and inflammatory responses to $H$. pylori infection Scand J Gastroenterol Suppl 215:3-10

19. Bodger K, Crabtree JE (1998) Helicobacter pylori and gastric inflammation. Br Med Bull 54(1):139-150

20. Yoshida N, Granger DN, Evans DJ, Graham DY, Anderson DC (1993) Mechanism involved in H. pyloriinduced inflammation. Gastroenterology 105:1431-1440

21. Kurose I, Granger DN, Evans DJ, Evand DG, Graham DY, Myiaska M et al (1994) H. pylori-induced microvascular protein leakage in rats: role of neutrophils, mast cells and platelets. Gastroenterology 107:70-79

22. Yamaoka Y, Kita M, Kodama T, Sawai N, Tanahashi T, Kashima K et al (1998) Chemokines in the gastric mucosa in $H$. pylori infection. Gut 42(5):609-617

23. De Koster E (1993) Microbiological aspects of $H$. pylori. Eur J Gastroenterol Hepat 5:S33-S35

24. Ahmed A, Holton J, Vaira D, Smith SK, Hoult JRS (1992) Eicosanoid synthesis and H. pylori associated gastritis: Increase in leukotriene $\mathrm{C} 4$ generation associated with $H$. pylori colonization. Prostaglandins 44:75-86

25. Maseri A, Biasucci LM, Liuzzo G (1996) Inflammation in ischaemic heart disease. Br Med J 312:1049-1050

26. Mendall MA, Patel P, Ballam L, Strachan D, Northfield TC (1996) C reactive protein and its relation to cardiovascular risk factors: a population based cross sectional study. Br Med J 312:1061-1065 
27. Fox AW, Davis RL (1998) Migraine chronobiology. Headache 38(6):436-441

28. Robbins L (1994) Precipitating factors in migraine: a retrospective review of 494 patients. Headache 34(4):214-216

29. Brewerton TD, George MS (1990) A study of the seasonal variation of migraine. Headache 30(8):511-513

30. Logan RPH (1996) The ${ }^{13} \mathrm{C}$ urea breath test. In: Lee A, Megraud F (eds) $H$. pylori. Techniques for clinical diagnosis and basic research. WB Saunders, London, pp 74-81

31. Colucci D'Amato C, Alfano V, Giordano E, Marmolo T, Pizza V (1997) Le cefalee. Idelson, Naples, p 258
32. Ziegler DK, Paolo AM (1995)

Headache symptoms and psycological profile of headache-prone individuals. A comparison of clinic patients and controls. Arch Neurol 52:602-606

33. Covacci A, Censini S, Bugnoli M, Petracca R, Burroni D, Macchia G et al (1993) Molecular characterization of the $128-\mathrm{kDa}$ immunodominant antigen of Helicobacter pylori associated with cytotoxicity and duodenal ulcer. Proc Natl Acad Sci USA 90:5791-5795

34. Blaser MJ, Perez-Perez G, Kleanthous $\mathrm{H}$, Cover TL, Peek RM, Chyou PH et al (1995) Infection with Helicobacter pylori strains possessing CagA is associated with an increased risk of developing adenocarcinoma of the stomach. Cancer Res 55:2111-2115
35. Russo F, Messa C, Amati L, Caradonna L, Leoci C, Di Matteo G et al (1998) The influence of Helicobacter pylori eradication on the gastric mucosal content of epidermal growth factor, transforming growth factor-alpha, and their common receptor. Scand J

Gastroenterol 33(3):271-275

36. Lynch DA, Mapstone NP, Clarke AM, Sobala GM, Jackson P, Morrison L et al (1995) Cell proliferation in Helicobacter pylori associated gastritis and the effect of eradication therapy. Gut 36(3):346-350 